\title{
Breast Implant Associated Anaplastic Large Cell Lymphoma (BIA-ALCL) in axillary lymph nodes - a case report and review of 29 other cases from world literature
}

\author{
Przemysław Dymek ${ }^{1}$, Tomasz Błaszkowski ${ }^{1}$, Sandra Sienkiewicz ${ }^{1}$, Kajetan Kiełbowski ${ }^{1}$, \\ Honorata Mruk1, Magdalena Lewandowska², Aleksandra Kipczak¹, Maciej Szyld', Józef Kładny
}

${ }^{1}$ Department of General and Oncological Surgery, Pomeranian Medical University, Szczecin, Poland

${ }^{2}$ Department of Pathology, Pomeranian Medical University, Szczecin, Poland

Introduction. Breast Implant Associated Anaplastic Large Cell Lymphoma (BIA-ALC) is a new disease established by the WHO in 2016. BIA-ALCL is one of the most severe adverse effects of breast augmentation or breast reconstruction with the use of silicone implants.

Material and methods. In our report we present a case of a 46-year-old patient diagnosed with BIA-ALCL in the General and Oncological Surgery Clinic of the Pomeranian Medical University in Szczecin. This is one of the first described cases of this disease in Poland. Especially interesting is the fact that the lymphoma developed two years after the removal of the implants and the pathology occurred in the axillary lymph nodes. In order to compare the published case of BIA-ALCL we reviewed 29 cases from literature.

Results. We described the most clinically relevant factors. The age range of females analysed with diagnosed BIA-ALCL is between 27 to 87 years. The time from implant insertion to the appearance of the first symptoms varies. The use of textured implants seems to be one of the most important risk factors of novel lymphoma.

Conclusions. The patients with breast implants should be informed about the risk of BIA-ALCL and related symptoms. The number of articles about BIA-ALCL is minimal, therefore knowledge about the disease remains limited. There is a need to broaden knowledge about the pathological process, clinical manifestations, risk factors and medical tests crucial to achieve an accurate diagnosis.

Key words: breast implant, lymphoma, lymphadenopathy, PET-CT, Poland

\section{Introduction}

In 2016 the World Health Organization (WHO) established a new disease entity entitled Breast Implant Associated Anaplastic Large Cell Lymphoma (BIA-ALC) [1]. The first case of a 41-year-old woman after bilateral breast augmentation and associated lymphoma was published in 1997 [2]. Until November 2018, only 656 cases had been registered [3]. According to E. Berlin et. al., frequency is estimated at 1 per
30000 females with breast implants [4]. This recent, uncommon type of non Hodgkin's lymphoma originates from T-cell lineage and is characterised by the presence of peculiar antigen CD30 expression and the absence of Anaplastic Lymphoma Kinase (ALK) expression. The histopathological image presents specific large cells, called "hallmark cells" due to hoof-shaped nuclei [5]. In most patients BIA-ALCL manifests itself with effusion, associated breast oedema and related

\section{How to cite:}

Dymek P, Błaszkowski T, Sienkiewicz S, Kiełbowski K, Mruk H, Lewandowska M, Kipczak A, Szyld M, Kładny J. Breast Implant Associated Anaplastic Large Cell Lymphoma (BIA-ALCL) in axillary lymph nodes - a case report and review of 29 other cases from world literature. NOWOTWORY J Oncol 2020; 70: 244-249. 
discomfort. Additionally, enlarged axillary lymph nodes are frequently observed [6].

As BIA-ALCL is a new disease established by the WHO recently, little is known about its possible pathogenesis. Several theories have been developed and many centres perform research to understand this process correctly. Knowledge about this rare complication is crucial, as many women nowadays undergo breast reconstruction or augmentation. Most theories share the view that pathogenesis is connected to a chronic inflammatory condition developing in the breast. It might be initiated as a result of capsule scarring and the involvement of the surrounding tissue. Furthermore, the type of implant capsule seems to have a significant impact on the risk. The majority of women suffering from BIA-ALCL had textured implants instead of smooth ones. This could lead to increased bacterial growth which may also contribute to intensified leukocyte activation [7]. Chronic antigen stimulation can be an incentive for the T-lymphocytes to transform into breast implant associated-ALCL. In the lymphoma, Thelper cell types have been detected [5]. It has also been found that patients with BIA-ALCL have mutations of JAK1 and STAT3 genes. One of the theories suggests that it might have an influence on inflammatory-associated malignancies [8]. Currently, there is no information about surgical techniques that may increase the risks of the lymphoma developing. Moreover, researchers are attempting to find specific genetic factors that play a part in this process.

\section{Material and methods}

In this article, we present a 46-year-old woman diagnosed with BIA-ALCL, 11 years after bilateral, aesthetic breast augmentation and two years after the removal of implants. We report one of the very few cases ever to be diagnosed in Poland. Furthermore, we reviewed 29 cases of the aforementioned disease from world literature.

\section{Case report}

A 46-year-old female was admitted to the General and Oncological Surgery Clinic in 2019. The patient had undergone aesthetic, bilateral breast augmentation in 2008. Nine years later, both implants were removed due to a suspicion of a rupture in the left implant. During this procedure, material from the implant pocket was collected for cytological examination. The procedure did not reveal the presence of malignant cells.

At the time of admission the patient complained of an axillary mass associated with periodically recurring inflammation and swelling in this area. Furthermore, dry skin and hair loss as well as fever and sweating was also reported. During the physical examination, three enlarged, left axillary lymph nodes were detected. Both breasts and the right axilla were without lesions. An ultrasound examination confirmed three enlarged lymph nodes measuring over $5 \mathrm{~cm}$, which were subjected to a core needle biopsy. A histopathological exa- mination revealed stromal connective tissue with numerous inflammatory cells, areas of necrosis and several solid foci of neoplastic large cells with cytological features of malignancy and CD30 immunohistochemical expression. Histological features together with the available immunohistochemical stainings suggested a non-Hodgkin's lymphoma, but the tissue sample was too small to evaluate the exact type of lymphoma. For this reason, a surgical biopsy was performed. During this procedure five axillary lymph nodes were collected. The dimensions of the largest node were $7,5 \mathrm{~cm} x$ $5 \mathrm{~cm} \times 3 \mathrm{~cm}$. The histopathological examination revealed that the neoplasm was composed of aggregates of pleomorphic large cells with features of malignancy, including irregularly shaped nuclei (fig. 1A). Aside from tumour cells, numerous T-cell lymphocytes, plasma cells, and necrotic fields with eosinophils were seen (fig. 1B). The cells were strongly positive for the CD30 antigen (fig. 1C) Additionally CD3, CD4, CD5, CD43, CD99, MUM1 expression was also confirmed. ALK expression was negative (fig. 1D) and the proliferation index was approximately $70 \%$. The fact of the previous breast augmentation procedure in correlation with the obtained test results allowed a diagnosis of BIA-ALCL.

The patient underwent PET-CT, which did not show any areas of increased 18F-FDG activity. Adjuvant treatment was limited to chemotherapy. Follow-up tests, performed after 3, 6 and 12 months, did not reveal any signs of a recurrence in the process.

\section{Review of $\mathbf{2 9}$ case reports in world literature}

In order to compare our analysed case of BIA-ALCL, we reviewed 29 other cases from world literature. Therefore, we describe the most clinically relevant factors in table I.

\section{Discussion}

The age range of the females in question with diagnosed BIA-ALCL was between 27 and 87 years. As much as 60\% of affected patients at the time of diagnosis were between 47 and 66 years old, whereas the average age of the analysed patients is approximately 53 years. The frequency of the disease in three age categories is featured in figure 2. The patient who reported to the General and Oncological Surgery Clinic was 46 years old. According to the presented data, risk at this age tends to increase.

The time from implant insertion to the appearance of the first symptoms of BIA-ALCL varies. In our study group, the range was from 0 to 22 years. In $65 \%$ of patients, symptoms occurred between 0 to 10 years from the day of implant placement. Figure 3 shows the correlation between the time of implant placement and the manifestation of symptoms. The presented patient developed symptoms 11 years after breast augmentation.

12 out of 30 reviewed cases reported the appearance of BIA-ALCL in patients with textured implants. Unfortunately, 

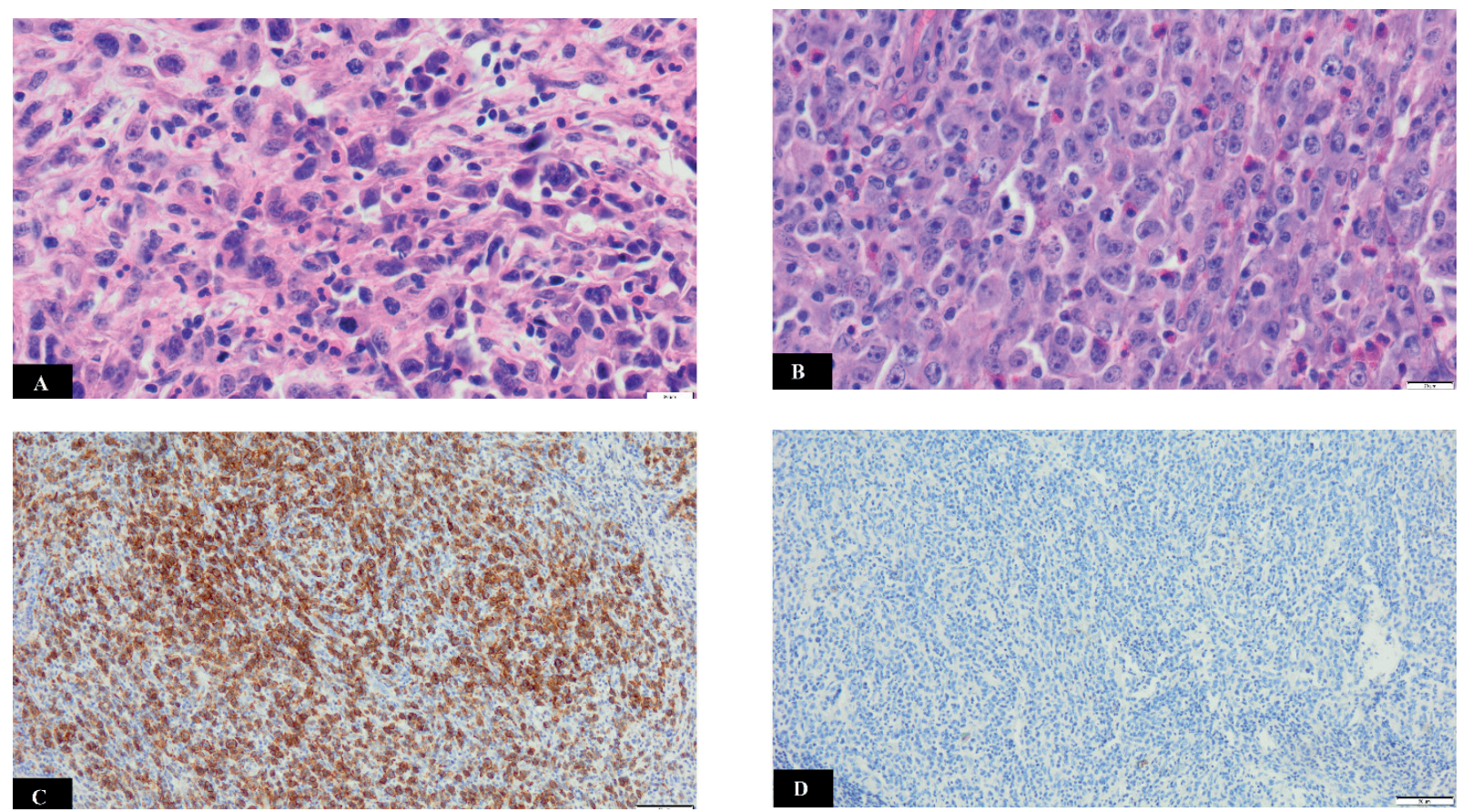

Figure 1. A - anaplastic large cells with characteristic irregular nuclei and numerous mitosis visible (H/E, 40X); $\mathbf{B}$ - the structure of the tumour with multiple mitosis and eosinophilic infiltration of cell clusters (H/E, 40X); C - CD30+ on IHC (20X); D - ALK negative on IHC (20X)

Table I. The most clinically relevant factors of reviewed cases

\begin{tabular}{|c|c|c|c|c|c|c|}
\hline Author & Age & $\begin{array}{l}\text { Time from implant } \\
\text { placement } \\
\text { to symptom } \\
\text { manifestations }\end{array}$ & $\begin{array}{l}\text { Textured } \\
\text { implants }\end{array}$ & $\begin{array}{l}\text { Swelling of } \\
\text { the breast or } \\
\text { axillary area }\end{array}$ & Lymphadenopathy & $\begin{array}{c}\text { Breast cancer } \\
\text { burden }\end{array}$ \\
\hline Taylor/2011[9] & 58 & 3 years & + & + & - & - \\
\hline Taylor/2011[9] & 37 & 4 years & + & + & - & - \\
\hline Taylor/2011[9] & 54 & 5 years & + & - & - & - \\
\hline Boer/2017[10] & 56 & 20 years & + & + & - & - \\
\hline Crevecoueur/2019 [11] & 58 & 7 years & + & + & - & - \\
\hline Crevecoueur/2019 [11] & 47 & - & + & + & - & - \\
\hline Carty/2011[12] & 57 & 22 years & + & - & - & - \\
\hline Alderuccio/2018[13] & 57 & 9 years & not reported & + & + & + \\
\hline Berlin/2017[4] & 58 & 2 years & not reported & + & + & - \\
\hline Hwang/2015[14] & 48 & 8 years & + & + & - & - \\
\hline Pastorello/2018[15] & 56 & 7 years & not reported & + & + & + \\
\hline Richardson/2017 [16] & 55 & 10 years & not reported & + & - & + \\
\hline Olack/2007[17] & 56 & 8 years & not reported & + & - & + \\
\hline Roden/2008[18] & 45 & 7 years & not reported & - & - & + \\
\hline Roden/2008[18] & 59 & 3 years & not reported & - & - & + \\
\hline Roden/2008[18] & 34 & 3 years & not reported & + & - & - \\
\hline Roden/2008[18] & 44 & - & not reported & - & - & - \\
\hline Adlard/2019[19] & 53 & 14 years & + & + & + & - \\
\hline Ezekwudo/2017[20] & 65 & - & + & + & - & - \\
\hline
\end{tabular}




\begin{tabular}{|c|c|c|c|c|c|c|}
\hline Fricke/2019[21] & 56 & 7 years & + & + & + & + \\
\hline Gardani/ 2019[22] & 75 & - & not reported & + & + & + \\
\hline Patzelt / 2017[23] & 27 & 7 years & + & - & - & - \\
\hline Gaudet/2009[24] & 87 & 10 years & not reported & + & - & + \\
\hline Gaudet/2009[24] & 50 & $<1$ year & not reported & - & - & + \\
\hline Keech/1997 [2] & 41 & 4 years & not reported & + & - & - \\
\hline Sahoo/2003[25] & 33 & 9 years & not reported & + & - & - \\
\hline Alobeid/2009[26] & 68 & 16 years & not reported & - & + & + \\
\hline Bishaara/2009[27] & 66 & 7 years & not reported & - & - & + \\
\hline Wong/ 2008[28] & 40 & 19 years & not reported & + & - & - \\
\hline Dymek et al. 2020 & 46 & 11 years & not reported & + & + & - \\
\hline
\end{tabular}

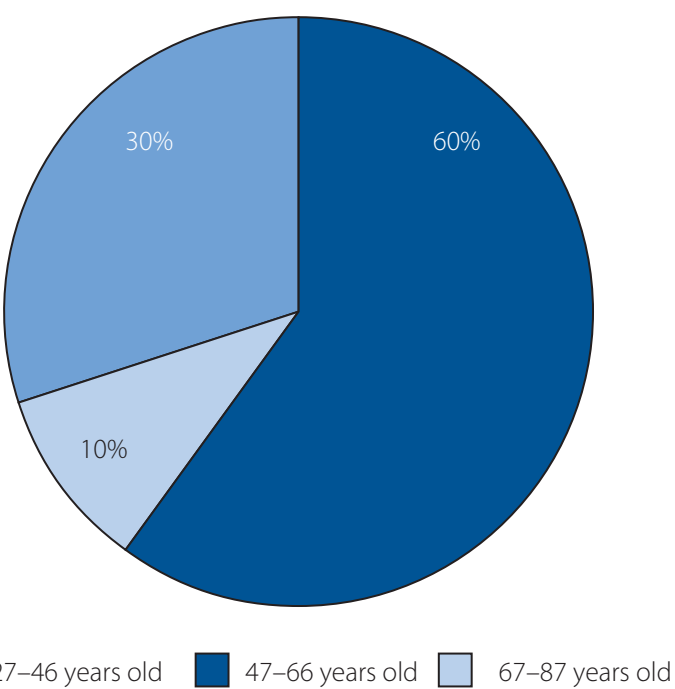

Figure 2. Age range of patients with $B I A-A L C L$

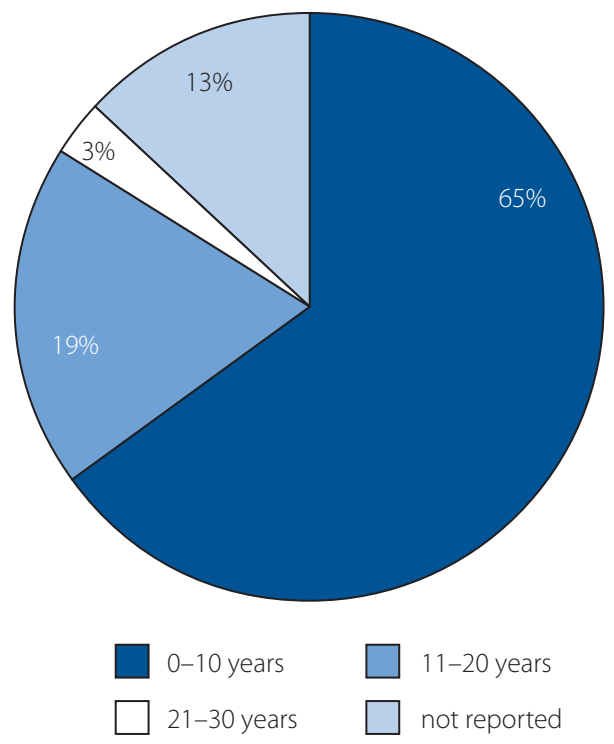

Figure 3. Time from implant placement to symptom manifestation including in our case, the type of implant was not specified in 18 of the cases. This may be due to the fact that females decide to undergo breast augmentation surgery because of aesthetic reasons and those surgeries are performed mainly in private clinics, therefore, the medical documentation can be difficult to access. The use of textured breast implants seems to be the most crucial and clinically important risk factor of BIA-ALC [23]. The research results of a clinical trial by Broody et al. showed that up to 171 of 173 BIA-ALCL cases were related to the textured structure of the breast implant [29]. It is crucial to broaden knowledge amongst patients about the possible complications arising from textured implants.

The reported 46-year-old female described a swelling of the axillary area due to developing lymphadenopathy. Only $26.7 \%$ of patients were diagnosed with lymphadenopathy in the studied case reports. In the literature, the coexistence of lymphadenopathy in the course of BIA-ALCL is estimated at 15\% [30]. Lymph node involvement might suggest a more aggressive course of BIA-ALCL compared to cases localised to the breast [31]. In our patient, special attention is drawn to the fact that lymphoma developed two years after the removal of implants and the pathology occurred in the axillary lymph nodes.

Another common manifestation is enlargement of the breast or axillary area, which was identified in $70 \%$ of reviewed patients.

In the analysed group, 40\% of patients were diagnosed with breast cancer formerly. Our patient had no previous oncological history. The summary of the clinical features of patients with BIA-ALC is presented in figure 4.

Considering the immunophenotype of all 30 patients, it is clear that there are some significant antigens related to BIA-ALCL. In 90\% of cases, expression of the CD30+ antigen was identified. CD3 and CD4 expression was found in 50\% of reviewed patients. 


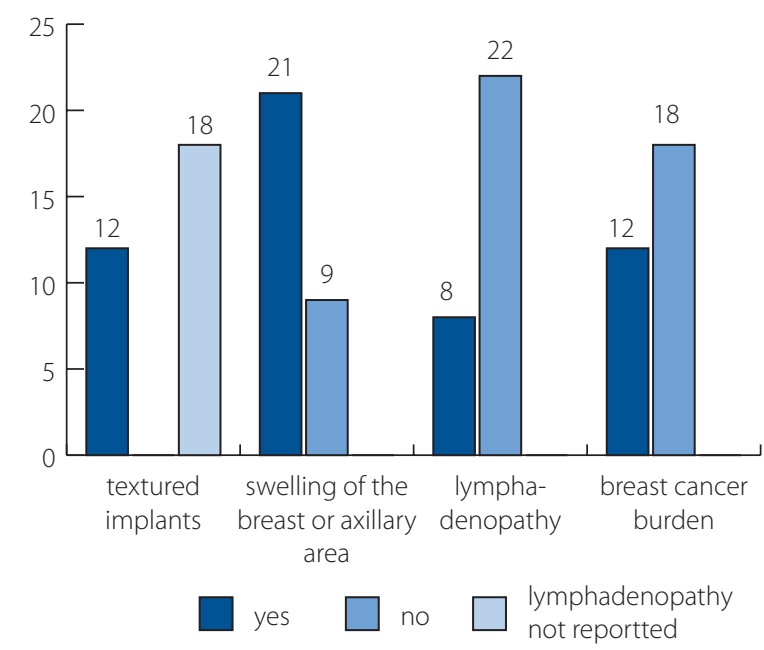

Figure 4. Summary of the clinical features of patients with BIA-ALCL

Patients with diagnosed BIA-ALCL are tested for expression of the ALK protein by the tumour cells [32]. Approximately 97\% of the reviewed cases did not express ALK. None of the cases was ALK positive and in one case ALK status was not reported. The IHC profile of our patient: CD30+ as well as CD3+ CD4+ and lack of ALK expression, corresponds with the immunohistochemical features from other case reports.

A crucial treatment for BIA-ALCL is surgical capsulectomy. An important factor during this procedure is to excise the whole capsule, including the adjacent tissue. There is no need to perform a mastectomy or to remove the surrounding lymph nodes, unless there are lymph nodes metastases [33]. To prevent oversight the metastasis, 18F-FDG PET-CT should be performed, preoperatively as well as postoperatively [34].

Currently, there are no strict guidelines for adjuvant treatment. Consequently, these treatment methods should be applied individually to the patients needs. Chemotherapy or radiotherapy are usually iniciated as adjuvant treatment [33].

\section{Conclusions}

Breast implants have rare but significant side effects. One of them is BIA-ALCL. The number of articles about BIA-ALCL is very much limited. The small number of published cases also make it difficult to find direct guidelines about managing this condition. That said, even though the frequency of described lymphoma is exceedingly uncommon, information on the risks and possible symptoms of BIA-ALCL should be presented to those patients interested in breast augmentation or breast reconstruction with the use of implants. Patients should be more aware of alarming symptoms, so they can then report to the hospital early before the progression of the disease.

In the case of symptoms like those presented in our patient, including the rupture of the implant or lymphadenopathy, BIA-ALCL should always be included in differential diagnosis. Furthermore, it is recommended that a $18 \mathrm{~F}-\mathrm{FDG}$ PET-CT examination should be performed, since this may reveal the possible spread of BIA-ALCL, which might otherwise be overlooked. Further research and analysis of BIA-ALCL cases will enable more successful future treatment.

\section{Abbreviations}

BIA-ALCL - Breast Implant Associated Anaplastic Large Cell Lymphoma

WHO - World Health Organization

ALK - anaplastic lymphoma kinase

JAK 1 - janus kinase 1

STAT 3 - signal transducer and activator of transcription 3

PET-CT - positron emission tomography - computed tomography

18F-FDG - 18F-fluorodeoxyglucose

$\mathrm{IHC}$ - immunohistochemistry

\section{Conflict of interest: none declared}

\section{Przemysław Dymek}

Pomeranian Medical University

Department of General and Oncological Surgery

ul. Unii Lubelskiej 1

71-252 Szczecin, Poland

e-mail:przemyslaw.dymek97@gmail.com

Received: 6 Jul 2020

Accepted: $21 \mathrm{Jul} 2020$

\section{References}

1. Swerdlow SH, Campo E, Pileri SA, et al. The 2016 revision of the World Health Organization classification of lymphoid neoplasms. Blood. 2016; 127(20): 2375-2390, doi: 10.1182/blood-2016-01-643569, indexed in Pubmed: 26980727.

2. Keech JA, Creech BJ. Anaplastic T-cell lymphoma in proximity to a saline-filled breast implant. Plast Reconstr Surg. 1997; 100(2): 554-555, doi: 10.1097/00006534-199708000-00065, indexed in Pubmed: 9252643.

3. Collett DJ, Rakhorst H, Lennox P, et al. Current Risk Estimate of Breast Implant-Associated Anaplastic Large Cell Lymphoma in Textured Breast Implants. Plast Reconstr Surg. 2019; 143(3S A Review of Breast Implant-Associated Anaplastic Large Cell Lymphoma): 30S-40S, doi: 10.1097/ PRS.0000000000005567, indexed in Pubmed: 30817554.

4. Berlin E, Singh K, Mills C, et al. Breast Implant-Associated Anaplastic Large Cell Lymphoma: Case Report and Review of the Literature. Case Rep Hematol. 2018; 2018: 2414278, doi: 10.1155/2018/2414278, indexed in Pubmed: 29607225.

5. Jones JL, Hanby AM, Wells C, et al. National Co-ordinating Committee of Breast Pathology. Breast implant-associated anaplastic large cell lymphoma (BIA-ALCL): an overview of presentation and pathogenesis and guidelines for pathological diagnosis and management. Histopathology. 2019; 75(6): 787-796, doi: 10.1111/his.13932, indexed in Pubmed: 31166611.

6. Leberfinger AN, Behar BJ, Williams NC, et al. Breast Implant-Associated Anaplastic Large Cell Lymphoma: A Systematic Review. JAMA Surg. 2017; 152(12): 1161-1168, doi: 10.1001/jamasurg.2017.4026, indexed in Pubmed: 29049466.

7. Jacombs A, Tahir S, Hu H, et al. In vitro and in vivo investigation of the influence of implant surface on the formation of bacterial biofilm in mammary implants. Plast Reconstr Surg. 2014; 133(4): 471e-80e, doi: 10.1097/PRS.0000000000000020, indexed in Pubmed: 24675200.

8. Blombery $\mathrm{P}$, Thompson $\mathrm{ER}$, Jones $\mathrm{K}$, et al. Whole exome sequencing reveals activating JAK1 and STAT3 mutations in breast implant-associated anaplastic large cell lymphoma anaplastic large cell lymphoma. Haematologica. 2016; 101(9): e387-e390, doi: 10.3324/haematol.2016.146118, indexed in Pubmed: 27198716.

9. Taylor KO, Webster HR, Prince HM. Anaplastic large cell lymphoma and breast implants: five Australian cases. Plast Reconstr Surg. 2012; 
129(4): 610e-7e, doi: 10.1097/PRS.0b013e3182450aae, indexed in Pubmed: 22456375.

10. de Boer M, van der Sluis WB, de Boer JP, et al. Breast Implant-Associated Anaplastic Large-Cell Lymphoma in a Transgender Woman. Aesthet Surg J. 2017; 37(8): NP83-NP87, doi: 10.1093/asj/sjx098, indexed in Pubmed: 29036941.

11. Crèvecoeur J, Jossa V, Somja J, et al. Description of Two Cases of Anaplastic Large Cell Lymphoma Associated with a Breast Implant. Case Rep Radiol. 2019; 2019: 6137198, doi: 10.1155/2019/6137198, indexed in Pubmed: 31346484.

12. Carty MJ, Pribaz JJ, Antin JH, et al. A patient death attributable to implant-related primary anaplastic large cell lymphoma of the breast. Plast Reconstr Surg. 2011; 128(3): 112e-118e, doi: 10.1097/ PRS.0b013e318221db96, indexed in Pubmed: 21775924.

13. Alderuccio JP, Desai A, Yepes MM, et al. Frontline brentuximab vedotin in breast implant-associated anaplastic large-cell lymphoma. Clin Case Rep. 2018; 6(4): 634-637, doi: 10.1002/ccr3.1382, indexed in Pubmed: 29636930.

14. Hwang MJ, Brown H, Murrin R, et al. Breast implant-associated anaplastic large cell lymphoma: a case report and literature review. Aesthetic Plast Surg. 2015; 39(3): 391-395, doi: 10.1007/s00266-015-0463-2, indexed in Pubmed: 25740078.

15. Pastorello RG, D'Almeida Costa F, Osório CA, et al. Breast implant-associated anaplastic large cell lymphoma in a Li-FRAUMENI patient: a case report. Diagn Pathol. 2018; 13(1): 10, doi: 10.1186/s13000-018-0688-x, indexed in Pubmed: 29370815.

16. Richardson K, Alrifai T, Grant-Szymanski K, et al. Breast implant-associated anaplastic large-cell lymphoma and the role of brentuximab vedotin (SGN-35) therapy: A case report and review of the literature. Mol Clin Oncol. 2017; 6(4): 539-542, doi: 10.3892/mco.2017.1170, indexed in Pubmed: 28413663.

17. Olack B, Gupta R, Brooks GS. Anaplastic large cell lymphoma arising in a saline breast implant capsule after tissue expander breast reconstruction. Ann Plast Surg. 2007; 59(1): 56-57, doi: 10.1097/SAP.0b013e31804d442e, indexed in Pubmed: 17589261.

18. Roden AC, Macon WR, Keeney GL, et al. Seroma-associated primary anaplastic large-cell lymphoma adjacent to breast implants: an indolent T-cell lymphoproliferative disorder. Mod Pathol. 2008; 21(4): 455-463, doi: 10.1038/modpathol.3801024, indexed in Pubmed: 18223553.

19. Adlard J, Burton C, Turton P. Increasing Evidence for the Association of Breast Implant-Associated Anaplastic Large Cell Lymphoma and Li Fraumeni Syndrome. Case Rep Genet. 2019; 2019: 5647940, doi: 10.1155/2019/5647940, indexed in Pubmed: 31392066.

20. Ezekwudo DE, Ifabiyi T, Gbadamosi B, et al. Breast Implant-Associated Anaplastic Large Cell Lymphoma: A Case Report and Review of the Literature. Case Rep Oncol Med. 2017; 2017: 6478467, doi: 10.1155/2017/6478467, indexed in Pubmed: 29225983.

21. Fricke A, Wagner JA, Kricheldorff J, et al. Microbial detection in seroma fluid preceding the diagnosis of breast implant-associated anaplastic large cell lymphoma: a case report and review of the literature. Case Reports Plast Surg Hand Surg. 2019; 6(1): 116-120, doi: 10.1080/23320885.2019.1593846, indexed in Pubmed: 32002457.
22. Gardani M, Bellini E, Villani G, et al. Breast implant-associated anaplastic large cell lymphoma: A rare case report of lymphoma in the form of a pericapsular solid formation. Breast J. 2020; 26(2): 247-251, doi: 10.1111/tbj.13541, indexed in Pubmed: 31489733.

23. Patzelt M, Zarubova L, Klener $\mathrm{P}$, et al. Anaplastic Large-Cell Lymphoma Associated with Breast Implants: A Case Report of a Transgender Female. Aesthetic Plast Surg. 2018; 42(2): 451-455, doi: 10.1007/s00266017-1012-y, indexed in Pubmed: 29101436.

24. Gaudet G, Friedberg JW, Weng A, et al. Breast lymphoma associated with breast implants: two case-reports and a review of the literature. Leuk Lymphoma. 2002; 43(1): 115-119, doi: 10.1080/10428190210189, indexed in Pubmed: 11908714.

25. Sahoo S, Rosen PP, Feddersen RM, et al. Anaplastic large cell lymphoma arising in a silicone breast implant capsule: a case report and review of the literature. Arch Pathol Lab Med. 2003; 127: e115-e118.

26. Alobeid B, Sevilla DW, El-Tamer MB, et al. Aggressive presentation of breast implant-associated ALK-1 negative anaplastic large cell lymphoma with bilateral axillary lymph node involvement. Leuk Lymphoma. 2009; 50(5): 831-833, doi: 10.1080/10428190902795527, indexed in Pubmed: 19330656.

27. Bishara MRY, Ross C, Sur M. Primary anaplastic large cell lymphoma of the breast arising in reconstruction mammoplasty capsule of saline filled breast implant after radical mastectomy for breast cancer: an unusual case presentation. Diagn Pathol. 2009; 4: 11, doi: 10.1186/17461596-4-11, indexed in Pubmed: 19341480.

28. Wong AK, Lopategui J, Clancy S, et al. Anaplastic large cell lymphoma associated with a breast implant capsule: a case report and review of the literature. Am J Surg Pathol. 2008; 32(8): 1265-1268, doi: 10.1097/ PAS.0b013e318162bcc1, indexed in Pubmed: 18594466.

29. Brody GS, Deapen D, Taylor CR, et al. Anaplastic large cell lymphoma occurring in women with breast implants: analysis of 173 cases. Plast Reconstr Surg. 2015; 135(3): 695-705, doi: 10.1097/ PRS.0000000000001033, indexed in Pubmed: 25490535.

30. Mehta-Shah N, Clemens MW, Horwitz SM. How I treat breast implant-associated anaplastic large cell lymphoma. Blood. 2018; 132(18): 1889-1898, doi: 10.1182/blood-2018-03-785972, indexed in Pubmed: 30209119.

31. DePaola NEK, Coggins H. Breast Implant-Associated Anaplastic Large Cell Lymphoma:What We Know. J Adv Pract Oncol. 2019; 10(1): 54-61, indexed in Pubmed: 31308988.

32. Kricheldorff J, Fallenberg EM, Solbach C, et al. Breast Implant-Associated Lymphoma. Dtsch Arztebl Int. 2018; 115(38): 628-635, doi: 10.3238/ arztebl.2018.0628, indexed in Pubmed: 30373708.

33. Clemens MW, Jacobsen ED, Horwitz SM. 2019 NCCN Consensus Guidelines on the Diagnosis and Treatment of Breast Implant-Associated Anaplastic Large Cell Lymphoma (BIA-ALCL). Aesthet Surg J. 2019; 39(Suppl_1): S3-SS13, doi: 10.1093/asj/sjy331, indexed in Pubmed: 30715173.

34. Siminiak N, Czepczyński R. PET-CT for the staging of breast implant-associated anaplastic large cell lymphoma. Nucl Med Rev Cent East Eur. 2019; 22(2): 90-91, doi: 10.5603/NMR.a2019.0015, indexed in Pubmed: 31482564. 